\title{
Charitable Dictators? \\ Determinants of Giving to NGOs in Uganda
}

\author{
July 14, 2017
}

\begin{abstract}
We play a dictator game in Uganda with students, civil servants, and individuals from the private sector. In the game, participants divide a sum of money between themselves and a local charity. In a turning a blind eye" treatment, participants are first given the choice of knowing the identity of the recipient. Finally, participants are asked whether they wish to additionally donate their own money. Contrary to many experimental findings, the average donation of non-students (civil servants) is significantly lower than that of students. Very few individuals donate their own money, despite $30 \%$ of participants donating the full endowment.
\end{abstract}

Keywords: Dictator game, charitable giving, philanthropy, Uganda 


\section{Introduction}

The growing importance of the middle class in Africa for growth, promoting good governance, and social welfare is increasingly emphasized by scholars in several disciplines. Resnick (2015) outlines recent progress in the understanding of this issue, and calls for further investigation to deepen the understanding of the attitudes and preferences of the middle class. This paper is a unique investigation of the charitable giving behaviour of middle class residents of Kampala, Uganda: University students, civil servants, and other urban residents, sampled in locations that are relatively expensive to visit in order to reach those at the higher end of the income distribution. Our interest in this sub sample of the non-poor living in developing countries stems from the belief that the social preferences and attitudes of the middle class to poverty and charitable giving are interesting and pertinent as development occurs. These preferences and attitudes may influence voting behaviour, occupational choice and other labour market outcomes, and contributions to voluntary public goods, including charitable giving, all of which have important implications for society. In Uganda, many middle and upper class urban residents (both local and expatriate) frequent expensive cafes, restaurants, and shopping centres in Kampala, as in other African cities, passing through areas of considerable deprivation to reach their destinations. In Uganda, average income is 715 USD per annum and $33.2 \%$ of the population live below the poverty line of 1.90 USD per day (2011 PPP). ${ }^{1}$ In contrast, in the cafes where our experiment was conducted with "wealthy" urban participants, a cup of coffee costs on average 2 USD, which is not dissimilar to the price in US and European coffee shops, where average incomes are much higher.

Einolf (2016) explores cross-cultural differences in charitable giving using survey data. He finds little difference in the value that people place on helping. However, he concludes that economic and political systems can facilitate the expression of the desire to help into

\footnotetext{
${ }^{1}$ Source: http://data.worldbank.org/country/uganda, last accessed June 30, 2016. GDP per capita data from 2015 and poverty headcount ratio data from 2012.
} 
formal charitable giving. Einolf (2016) notes that the political context is important because charitable giving is an activity that takes place within political systems, with government policies, tax systems, levels of corruption, stability, and financial regulation affecting how easily non-profits can organize themselves and solicit donations. Mattes (2015) also emphasizes how country context can mediate the behaviours and preferences of the middle class. Bekkers and Wiepking (2011) identify eight causal factors in philanthropy. These are: Awareness of need, which is often affected by personal experience; solicitation; costs and benefits of donating; altruism; reputation; psychological benefits (warm glow); values (in the choice of organization); and efficacy. Multiple motives occur within each individual and interact with one another. This study contributes to the literature within this framework by using the controlled experiment of a dictator game to understand a) differences between groups and b) whether participants turn a blind eye to need in order to give less. The experiment "switches off" the channels of awareness of need, solicitation, and costs and benefits by placing all participants in the same context, thus allowing us to explore the latter motives for giving; in particular reputation and efficacy.

In developed countries, our methodology of laboratory experiments in economics has primarily been conducted with students. Criticism of this has led research to compare the behaviour of students with non-student populations (see, for example, Belot et al., 2015; Falk et al., 2013). However, to our knowledge, such a comparison has yet to be conducted within a developing country. ${ }^{2}$ The setup of the experiment is a dictator game (DG) with a charity recipient. To participants, we did not frame the DG as an experimental game. Rather, we informed them that the research team was giving them a sum of money for their participation in the research and that they could choose whether to give away none, some, or all of the money to a third party. In the baseline treatment, participants were told that

\footnotetext{
${ }^{2}$ Several papers have compared the behaviour of students in developed countries to populations in developing countries, such as Henrich et al. (2001) and related articles, but none have compared students to non-students within a developing country.
} 
the third party was a charity operating in Kampala. They received the money and made the choice before completing a questionnaire. This design ensured that questions about poverty and the usefulness of charities would not influence their donation decision. In a "blind eye" treatment, outlined in detail below, participants were given the choice of whether to find out the identity of the third party with whom they were playing the game. This treatment was designed to parallel the experience of living amongst visible poverty, where it may be "easier" to choose to ignore the circumstances of those around you. The aim is not to criticize the use of student subjects, rather to compare their charitable giving decision with non-students.

We also compare the decisions of public/nonprofit and private sector workers. Besley and Ghatak (2005) outline a theoretical model whereby workers sort themselves according to "mission", allowing for the role of intrinsic motivation or preferences over the work of an organization. Serra et al. (2011) conduct a trust game with health workers in Ethiopia and find that intrinsic (philanthropic) motivation increases the likelihood of working in the non-profit sector. Cowley and Smith (2014) examine correlates of working in the public sector using the World Values Survey. Their overall conclusion is that there is a positive relationship between intrinsic motivation in many of their 51 study countries, but not all. Uganda does not have an entry in the survey but, in nearby Ethiopia and Rwanda, the authors do find a significant positive relationship between being a public sector employee and measures of intrinsic motivation (agreeing that it is important to help others or being active in charity or environmental work). Using our experimental design and by comparing public and private sector employees, we can investigate the relationship between sector of work and charitable giving using decisions involving real sums of money.

In addition to our standard dictator game, at the end of the survey, participants were asked if they wanted to add any of their own money to their donation. To our knowledge, whilst this is a fairly simple treatment, it has not previously been implemented. It is most similar to experimental studies and surveys in which participants play a dictator game with 
income earned during the study (for example, as in Bekkers et al. (2007) and Cherry et al. (2002)). In the setting of our modified DG with real money and a charity/NGO partner, we do not argue that the dictator game is identical to the circumstances in which people normally find themselves. However, the addition of this final question more closely replicates such situations. Bardsley (2008) notes that, in everyday life, individuals may be asked on a daily basis either to contribute money to a homeless person on the street or to donate to a charitable organization. These situations can be seen as an individual "playing" a dictator game with their own money. Despite almost 85 per cent of our subjects giving a positive amount of their windfall gain to their chosen charity and almost 30 per cent of participants giving away the full amount, only 5 per cent (or seven people in a sample of 149) chose to give any of their own funds.

The text is organized as follows. In the next section, we review the related literature. Section 3 describes the game design in detail and specifies the five hypotheses we test with our experimental design. Descriptive statistics and results are presented in section 4. Section 5 concludes and outlines potential areas of future research.

\section{Literature Review: Experimental Games}

A growing number of experimental games have been conducted in developing countries investigating the behaviour of the poor (Cardenas and Carpenter, 2008). However, the better-off members of the urban population who are not living in poverty, yet live in a developing country, have rarely been experimental subjects (with the exception of students attending African universities (e.g. Ashraf et al., 2006).

In the dictator game, participants are given an endowment (real or in token form) and asked to divide the amount between themselves and a third party. There is no strategic 
interaction, and thus no fear of reprisal, as the third party has no agency. Therefore, giving a non-zero amount has been interpreted as altruism, warm-glow (impure) altruism, or the existence of other regarding preferences, such as, inequality aversion (Fehr and Schmidt, 1999) - though this interpretation is disputed (List, 2007; Bardsley, 2008). Many variants of the game exist. Alternative treatments have been developed with regard to the size of the endowment, the sample of interest, real or token endowments, earned or unearned endowments, initial allocations (giving versus taking), and the identity of the recipient.

Several authors have reviewed the numerous papers employing dictator games, including notably Camerer (2003), Cardenas and Carpenter (2008), and Engel (2011). Engel (2011) conducts a review and meta-study of hundreds of dictator games and calculates the average donation by dictators across all studies as $28 \%$ of the endowment. Regarding the distribution, $36 \%$ of dictators give nothing, $16 \%$ give half, and just $5 \%$ give the full amount. Engel (2011) also finds that when real money is used, the proportion of dictators who give away nothing decreases and the proportion who give away everything increases significantly.

Our study takes place in Uganda and the participants are likely to be much wealthier than those who have thus far been sampled in an African setting. Engel's (2011) meta-analysis finds that "Western" participants are more likely to give zero, but are also more likely to give away everything, than participants from developing countries, though the average amount given is not significantly different in a meta-regression. Duch and Palmer (2004) find that in Benin, with a sample of non-students, $7.8 \%$ give nothing away in a (hypothetical) dictator situation. Henrich et al. (2005) conduct several games including a DG across a broad range of societies and find that in small-scale societies in Africa and Latin America (Orma in Kenya, Hadza in Tanzania, and Tsimane in Bolivia) almost nobody offers zero and that mean offers are much higher than in ("Western") student studies at 31, 20, and 32 percent respectively. Whilst most early DG research used a pool of students to recruit participants, some recent 
studies have also recruited non-students, and found that students tend to give significantly less than non-students (Belot et al., 2015; Engel, 2011; Falk et al., 2013).

Engel (2011) in his meta-study, finds that "deserving recipients" receive considerably larger shares of the endowment. The proportion of those who give the full amount to a charity or an individual described as more deserving rises to $20 \%$ from almost zero and those who keep everything reduces to $20 \%$ from just under 40\%. Eckel and Grossman (1996) is the first laboratory experiment to replace an anonymous partner with a deserving cause (a charity; the American Red Cross) as the partner. They find that student participants are more generous in their contributions to the charity than when paired with an anonymous peer. The authors also find that women are more generous than men. Carpenter et al. (2008) expanded this alternative to allow (student and non-student) participants a choice between 13 charities (participants could also choose a charity of their choice if they preferred). The authors also find that students, on average, give less than community members, though more than in Eckel and Grossman (1996). Community members wrote down their own charity more often than students (interpreted as possibly indicating stronger preferences for charities) and $40 \%$ of participants allocated the full amount to the charity (100 USD). Fong and Luttmer (2011) find that perceived worthiness of the recipients does significantly increase giving to the charity. Small et al. (2007) summarize the evidence demonstrating that people tend to donate more to 'identifiable victims' (i.e. an example of a specific person who would be affected by the donation) rather than statistical victims (e.g. 10,000 people die of $\mathrm{X}$ per year). They show that a treatment alerting participants to such heuristic biases does reduce the amount given to the identifiable victims but does not increase the amount given to statistical victims, resulting in an overall reduction in giving. Banuri and Keefer (2015) find evidence of pro-social motivation increasing giving in charity dictator games for civil servants in Indonesia. 
A multitude of studies have found that giving in dictator games appear to show people as more altruistic than in everyday life. Bardsley (2008) makes the point that "(s)ince we all face the dictator game all day, every day, it could be argued, the experimental design would appear to score highly on conventional standards of ex-ante external validity"(p.123). Levitt and List (2007) however outline five crucial peculiarities of laboratory experiments that may lead pro-social behaviour to be significantly different from 'real life' behaviour. "1) the presence of moral and ethical considerations; 2) the nature and extent of scrutiny of one's actions by others; 3) the context in which the decision is embedded; 4) self-selection of the individuals making the decisions; and 5) the stakes of the game." (p.154). Carlsson et al. (2013) also find other differences between lab and field behaviour, interpreting it as the importance of the environment in determining choices. Our experiment includes an unearned endowment and the additional possibility of giving one's own funds. This possibility is similar to an earned endowment though not precisely the same. Though these are important considerations, we do not see any reason to think that any of these peculiarities would have differential impacts on our three subject types or the two treatment groups.

Finally, "experimenter demand" effects may lead subjects to contribute more in an experimental setting because they believe that this is what they are supposed to do or because they want to please the experimenter (Carpenter et al., 2008). Both List (2007) and Bardsley (2008) argue that the generosity observed in dictator games may be an artefact of experimentation. Both authors construct treatments which allow dictators to take money away from their partner and show that this leads to a reduction in giving. Zizzo (2013) criticizes dictator games as being uninformative about altruistic preferences, due among other reasons, to their being easily influenced by such things as framing and experimenter demand effects.

In our set-up (described in section 3), the experimenters were three white females aged $30-45$, so there is a strong possibility that this may lead to an increase in average giving (Cilliers et al., 2013). Though we compare the average amount donated in our experiment 
to the existing literature, this is is not the primary focus of study. We are interested in between-subject behaviour and the impact of a randomly assigned sub-treatment. We argue that experimenter demand effects are unlikely to explain the differences in between-subject behaviour observed in our study. The random nature of the treatment also limits the possible impacts of experimenter demand effects. Cilliers et al. (2013) vary foreigner presence when conducting behavioural games in Sierra Leone. They find that the presence of a white foreigner increases contributions in a dictator game. Moreover, the impact of the foreigner presence is smallest among participants where the perceived power differential between the player and the experimenter is smallest. Therefore, if similar experimenter demand effects are present in our study, we would expect them to be smallest for our "wealthy" urban participants, and either no different between the Ministry of Finance personnel and the university students, or, if anything, smaller for the civil servants. This would mean that our estimates would if anything underestimate the differential effects between subject types.

In our treatment, we aim to test the idea that some wealthy individuals who live in an environment where they are surrounded by substantial poverty, including begging on the street, may be prone to the idea of "turning a blind eye" to the situation. We test whether, when given the option of not receiving any information regarding the recipient, people simply choose to take the money and "not think about it". This is related to a small literature which has offered exit options in dictator games, though not precisely the same (Dana et al., 2006; Broberg et al., 2007; Jacobsen et al., 2011).

\section{Game Design and Sample Selection}

A sample of 149 participants in Kampala, Uganda participated in the study in March and April 2013. The sample was stratified by sector and potential participants were approached at the Ministry of Finance, the College of Business and Management Sciences at Makerere 
University, and several relatively upscale cafes in Kampala. Each potential participant was approached by one enumerator and asked if they were willing to participate in a research study. They were then given a one-page document briefly outlining the project. The document was intended to provide sufficient information to enable potential participants to decide whether they wanted to participate in the study.

The document stated that the research is part of an economic study of people living and working (or studying) in Kampala and that the information collected was only to be used by researchers for the purpose of academic analysis. Their participation would take approximately 10 minutes and they would be asked to make some decisions and to complete a short questionnaire of 2 pages. They were informed that no one, including the researchers, would be able to see their individual responses and that they themselves would place all of their responses in a sealed envelope. The research team would then open the envelope together with others, so no one would be able to identify any individual answers or choices. Moreover, the participant would not be asked for their name and no identifying information about them would be used in the research.

Those individuals who agreed to participate in the study were randomly assigned to one of two treatments. The first treatment is a standard dictator game played with a charity while the second treatment introduces an additional choice by the participant which reveals the identity of the third party with whom they are playing the game. These two treatments are described below.

In the standard treatment, each participant is given an envelope which contains the instructions for their participation. The instructions state that the research team is giving them 20,000 Ugandan Shillings (UGX) for participating in the research project. At the time of the study, 20,000 UGX was equal to approximately 8 US dollars. The 20,000 UGX was placed in an envelope labelled "FUNDS" in 2,000 UGX bills. The instructions then state that the participant is to decide to give none, some, or all of the 20,000 UGX to one charity 
of their choice from a list of 23 charities operating in Uganda $^{3}$ listed on the back of the instruction sheet. The charities include both local and international NGOs operating in Uganda in sectors concerning children, poverty alleviation, human rights, or animal rights, and include both religious and non-religious organizations. Participants placed the amount of money they wished to keep for themselves in the envelope labelled "TAKE WITH YOU" which they took with them at the end of the activity, regardless of whether they had kept any money for themselves. Participants also placed the amount of money they wished to give to the charity in the envelope labelled "LEAVE WITH RESEARCH TEAM" and returned it to the research team, regardless of whether they gave any money to a charity, along with the instructions and the completed questionnaire.

In, what we will refer to as, the "identity" treatment, participants were given the same instructions as those in the standard treatment. However, instead of choosing between keeping the money for themselves and giving it to a charity of their choice, the instructions stated that they were to decide to give none, some, or all to a third party. They were also given the option of finding out the identity of the third party, at no cost, by opening an envelope labelled "IDENTITY". If the participant chose to open the "IDENTITY" envelope, the instructions stated that the third party was a charity of their choice from the same list of 23 charities as in the standard treatment. The instructions also stated that even if they chose to open the "IDENTITY" envelope, they were under no obligation to give away any of the 20,000 UGX. This treatment was included in order to analyze the idea that some individuals "turn a blind eye" to the poverty surrounding them by ignoring the problem. Therefore, our hypothesis is that individuals who received the "IDENTITY" treatment would give, on average, less to the charity than those who received the standard treatment. We also analyze the characteristics of individuals who choose to open the "IDENTITY" envelope, compared

\footnotetext{
${ }^{3}$ The 23 charities were chosen based on previous research conducted by the authors in Kampala. In that study, participants were asked to choose a charity to which they wanted to donate project funds. The 23 most popular charities were included here.
} 
to those who do not.

After making their decisions regarding the distribution of the 20,000 UGX, participants completed a brief questionnaire regarding their socio-economic characteristics as well as their attitudes regarding the general performance of charities/non-governmental organizations in Uganda. In addition, those individuals who were randomly assigned to the standard treatment, as well as those who opened the "IDENTITY" envelope, were asked questions regarding their choice of charity. A final question asked participants if they wished to add their own money to the amount already placed in the envelope for the charity. If they chose to do so, they were asked to include this money with the questionnaire when they returned the envelope containing all of the project documents. This additional question was included to investigate one of the puzzles of dictator games; that people are generally more generous/altruistic in such games than they appear to be in everyday life. One of the proposed explanations for this finding, noted above (Bardsley, 2008), is that such dictator games rely on individual choices over a windfall gain and not over their own money. This additional question is relevant only for those participants who chose to give the entire 20,000 UGX to a charity.

With this experimental set-up, we test the following hypotheses concerning behaviour: Hypothesis 1: The provision of an "exit option" will decrease the amount donated.

Hypothesis 2: Allowing the amount given to exceed the endowment will increase the amount donated.

Hypothesis 3: An individual's ranking of the charity will be positively correlated with the amount donated.

Hypothesis 4: The amount donated will be increasing in the perceived 'worthiness' of the recipient.

To our knowledge, hypothesis 2 has not been directly tested previously. The most closely related concept is games in which subjects "earn" real money in a task and then play a 
dictator game (e.g. Small and Loewenstein, 2003, where participants complete a survey to earn 5 USD and then play a dictator game). Such studies find that giving is significantly reduced when the endowment is earned (see also literature review above). In related work, Clark (2002) asks participants to bring their own money to an experimental session, and Harrison (2007) shows in an analysis of this data that, in a public goods game, participants do change their behaviour when playing with their own money.

To test hypotheses 3 and 4, we use information from the post-game questionnaire related to charitable giving and the worthiness of recipients. We asked all respondents if they agreed or disagreed (and how strongly) with the following statements. Firstly, that "NGOs are doing good work in Uganda.". In addition, for those respondents who played our standard dictator game and those in the "identity" treatment group who chose to find out the identity of their partner, we asked "On a scale from 1-10 where 1 is very poor and 10 is excellent, how would you rate this charity?". The quality of a charity can be learned by experience with the charity, either directly or indirectly through research on the effectiveness of the charity. Individuals' opinions of the quality of the charity relate directly to the benefits they foresee from their donation. We also hypothesize that the more people agree with the statement that "Some people are poor through no fault of their own.", the higher the utility they receive from donating. This statement relates to how deserving one believes recipients are of the charity's help (conditional on the charity being related to poverty alleviation).

We define three occupation categories in our setup: University students, those employed in the nonprofit sector (including Ministry of Finance personnel), and those employed in the private sector (including the self-employed). We assume that average income is lowest for students, followed by the nonprofit sector. Those participants in the private sector, in addition to two Ugandans and 18 non-Ugandans employed in the nonprofit sector, were interviewed in relatively upscale cafes. Therefore, we assume that the average income level for those from the private sector is the highest amongst our three sectors. As noted in the 
literature review, almost all studies comparing students to non-students have found them to behave less generously in the DG. Whether this is an income effect or a "student" effect, we would a priori expect students to give less than non-students. All of the Ministry of Finance personnel are Ugandan, as are most of the Makerere University students, the cafe-goers include both Ugandans and expatriates.

\section{Results}

\subsection{Sample Characteristics by Treatment Status}

Tables 1 and 2 investigate the success of the randomization of the game treatments. We refer to those participants who were randomly assigned to play the version of the game with the exit option as the treatment group and those who play the standard game without the possibility of an exit option as the control group. The treatment was randomly assigned to participants and stratified by the location of the experiment (Ministry of Finance, Makerere University, cafe). In addition to the data from the dictator game, participants' socio-demographic characteristics and attitudes to NGOs in general, and to their chosen NGO in particular, were collected. Unfortunately, of the 149 participants, 28 participants did not fully complete the questionnaire and are, therefore, excluded from any analysis which includes the additional covariates measuring attitudes. Given our small sample sizes, in table 1, we, therefore, present the success of the randomization for the full sample of participants while in table 2, we limit the sample to the sub-sample of 121 participants who fully completed the questionnaire. Column 1 of tables 1 and 2 present the mean and standard deviation for the full sample while column 2 (3) presents these same statistics for the treatment (control) group. Column 4 presents the difference between the treatment and control group means. We expect to find no statistically significant differences between the treatment and the control group if the randomization was successful. 
Thirty-nine percent of the sample received the identity treatment (58 individuals). For those participants who do not complete the questionnaire, the only information available (in addition to the outcomes of the dictator game) is the location of the experiment, their gender, nationality (Ugandan or non-Ugandan), age, and sector of activity. Overall, the average age in the sample is relatively young (32) and education levels are relatively high compared to the Ugandan average. The majority of participants (71\%) are Ugandan. We find no statistically significant differences between the treatment and the control group in the location of the experiment (as expected given the stratified randomization). Of the 12 variables in table 1 , the only statistically significant difference between the treatment and control groups for the full sample is a difference in mean age of approximately three years. In table 2 , we show that there are no statistically significant differences in gender, age, level of education, or nationality between treatment and control group participants in the sub-sample who fully completed the questionnaire. The only imbalance in the treatment assignment is the location of the experiment/sector of activity (which are highly correlated). The proportion of students who were treated is slightly higher (significant at the $10 \%$ level). ${ }^{4}$ We, therefore, control for treatment (and sector or education level, though not both as they are highly correlated) in all specifications in our investigation below.

In figure 1, we first present a histogram of the donation amounts by sector of activity (left hand panel) for both treatments combined. Overall, the average amount donated is just under one-half of the endowment. Moreover, we find substantial variation in the amount donated with many participants giving either zero or 2,000 UGX and many, especially those from the private sector, donating the full amount. As we noted above, there are more nonUgandans from the private sector. We, therefore, present the histogram for the Ugandan sub-sample in the right hand panel of figure 1. There is still a clear difference in the dis-

\footnotetext{
${ }^{4}$ Students appear to have completed the questionnaire more carefully and, hence, have fewer missing observations.
} 
tribution of individuals from the private sector, who give more and are much more likely to give the full amount. The difference between the nonprofit sector and students is almost indistinguishable, which we formally test below. Students are more likely to give nothing than other participants. In a t-test, students are more likely to give nothing than non-students (in a two-sided t-test, the difference is significant at the $10 \%$ level for the full sample of both Ugandans and non-Ugandans).

Table 3 compares the behavioural decisions from the game across the two randomly assigned game treatments, and overall, for the full sample of participants (panel A) and the sub-sample who completed the questionnaire (panel B). These simple differences (without additional control variables) in the behavioural decisions of the participants across treatment status are initial estimates of the impact of the treatment. As expected, a very high proportion of participants did give something away (over 80\%) and the average donation was close to half of the endowment. The treatment significantly reduced the amount donated, by 2,500 UGX (full sample: t-test; $\mathrm{p}=0.0559$, Mann-Whitney non-parametric test; $\mathrm{p}=0.0276$ ). The treatment also increased the proportion of participants keeping the full amount, from $11 \%$ of the control group to $24 \%$ of the treated participants (full sample: t-test; $\mathrm{p}=0.033$, Mann-Whitney test; $\mathrm{p}=0.034)$. 45 of the 58 participants assigned to the treatment group chose to open the envelope in order to find out the identity of the recipient (78\%). The results are similar in the sub-sample of participants who completed the questionnaire (panel B of table 3). The t-test for the treatment effect becomes just insignificant, though, as for the subgroups in the full sample above, a one-tailed t-test shows a significant reduction in giving of 2,000 UGX ( $\mathrm{p}=0.084$, Mann-Whitney $\mathrm{p}$-value=0.088). The finding that a significantly larger proportion of the treated group keeps the full amount remains significant (23\% vs 12\%). Finally, 33 of the 43 participants assigned to the treatment group and who completed the questionnaire chose to open the identity envelope $(77 \%)$.

Table 4 investigates the decisions from the game by the participant's choice of whether or 
not to open the identity envelope. Panel A of table 4 compares participants assigned to the treatment group between those who chose to open the identity envelope and those who chose not to. Those participants who chose to open the envelope and learn the identity of their partner in the game gave significantly more than those who chose not to; on average, over 6,000 UGX more. They were also more likely to give away the full amount and less likely to keep the full amount. Panel B compares the decisions of those participants who chose to open the envelope with the control group. As expected, we find no significant differences in their choices in the game.

\subsection{Regression Analysis}

Table 5 presents the results of a regression combining the treatment and sector dummies. Column 1 replicates the results of the first row of table 3. With the inclusion of controls for the two sectors of non-students, with students as the excluded category, in column 2 , the estimate of the impact of the treatment does not change significantly. Participants from the nonprofit sector do not donate significantly more than students, unlike those from the private sector. We include a control variable for the nationality of the participant as there are more Ugandans in both the student (77\% of students in the sample are Ugandan) and the nonprofit sector ( $75 \%$ of those working in the nonprofit sector are Ugandan) compared to

the private sector (of which only $57 \%$ are Ugandan) and there may be differences in wealth between the Ugandan and non-Ugandan participants. In column 3, we include interaction effects between the treatment and sector of activity. Though these interactions are not significant, they are suggestive of the hypothesis that students are more sensitive to the treatment than the non-student sample. We, therefore, conduct t-tests and Mann-Whitney non-parametric tests for differences in means in each sector separately. As in the regression, the two tailed test is not significant for any of the sectors. However, in a one-sided t-test (where H1: The treatment reduces the donation amount), both students and those working 
in the nonprofit sector show reductions in giving that are almost statistically significant (at the $11.5 \%$ level of significant for students and the $10.48 \%$ level for those in the nonprofit sector). The Mann-Whitney test shows a statistically significant reduction in giving due to the treatment for those participants in the nonprofit sector.

Given the differences in nationality between the sectors of activity and the likely link between nationality and wealth (in our sample of participants), in table 6 we present the results of the same estimations as those in table 5 for the sub-sample of Ugandans only. Qualitatively, the results presented in table 5 for the full sample hold for the Ugandan subsample. The treatment variable loses its statistical significance in columns 1 and 2 but the magnitude of the estimated coefficients are largely unchanged.

In table 7 , we include further participant characteristics in our regression analysis. As previously noted, this reduces our sample size to 121 participants. In column 1, we include gender and age to our initial specification (table 5). The treatment and private sector variables are no longer significant. In column 2, we investigate differences in the amount donated within each sector of activity between Ugandans and non-Ugandans. We do this by including an interaction between being Ugandan and being in the nonprofit sector and between being Ugandan and being in the private sector ${ }^{5}$. Ugandans in the nonprofit sector (54 out of 55 of those who completed the questionnaire work for the Ministry of Finance) give significantly less, than students even, with a point estimate of over 11,000 UGX (column 2). Non-Ugandans in the nonprofit sector give significantly more than students, by over 7,000 UGX while non-Ugandan participants in the private sector also give more than 6,000 UGX more than students though this result is not statistically significant.

In columns 3 through 5, we examine correlations between the amount given and the responses to the questions regarding social attitudes. People were asked if they agree with

\footnotetext{
${ }^{5}$ We do not include an interaction between student and being Ugandan as only 7 of 37 students are non-Ugandan.
} 
the statement "People are poor through no fault of their own" on a Likert scale from 1-5; a measure of the deservingness of the poor (as discussed above). The distribution of responses is presented in figure 2 (left hand panel). Non-Ugandans are much more likely to agree with the statement than Ugandans with nearly $60 \%$ strongly agreeing with the statement. Very few participants, both Ugandan and non, disagree with the statement. We, therefore, create a dummy variable for strongly agree ( 5 on the Likert scale) and include this in the regression in column 3. The coefficient is positive and statistically significant at the $10 \%$ level, suggesting an average increase in giving of just under 3,000 UGX.

Individuals were also asked, on a Likert scale from 1-5, if NGOs were doing good work in Uganda. Figure 2 (right hand panel) shows the distribution of responses by nationality. Opinions are very positive regarding NGO work, especially among Ugandans. More than $70 \%$ of respondents either agree or strongly agree with the statement, with Ugandans being more likely to agree or strongly agree. Table 7, column 3, shows that strongly agreeing that NGOs do good work in Uganda is negatively correlated with giving. We include an interaction between this variable and Ugandan in column 4. This shows the negative relationship as significant for non-Ugandans and much smaller and only weakly significant (at the 10\% level) for Ugandans. However, in column 5 when we control for education, the effect disappears for Ugandans. The negative relationship holds for non-Ugandans only.

One possible explanation for this finding is that individuals who believe that NGOs are doing good work in Uganda also believe that are able to do good work because they are already well funding and, therefore, donate less. Similarly, individuals who believe that NGOs are not doing good work may do so because they believe that they are not well funded, and therefore, give more in our experiment. Either of these statements, or both, can explain these seemingly counter-intuitive results. Unfortunately, we did not collect data on the beliefs of participants regarding the funding adequacy of NGOs in Uganda.

Finally, participants in the control group and those who opened the identity envelope 
in the treatment group were asked to rank the NGO that they personally chose on a scale from 1 (very poor) to 10 (excellent). We include this ranking in a regression of the amount donated. The sample size drops due to the participants in the treatment group who chose to not open the envelope, but the ranking of the NGO is not a significant determinant of the amount given (results available upon request).

In table 3 , in the simple comparison between the treatment and control groups, we find a significant treatment effect on whether participants kept the full amount (gave nothing). We investigate this further in tables 8 (full sample) and 9 (sub-sample who completed the questionnaire). We then briefly discuss the characteristics of those participants who gave the full endowment and, in addition, gave some of their own money.

In table 8 , we present linear probability model results where the dependent variable is a dummy variable which equals one if the participant kept all of the money for themselves and zero otherwise. ${ }^{6}$ In columns 2 and 3, we include an interaction term between the treatment and sector of activity status allowing for the impact of the treatment to vary between the participants from the three sectors.

In column 1, we show that the treatment is statistically significant and increases the likelihood of keeping the full amount by 0.13 for the omitted category of students. In columns 2 and 3 , the interaction terms between the treatment and the sectors of activity are not statistically significant. However, their inclusion increases the magnitude of the simple treatment variable to $0.22 / 0.23$. Though, the interaction terms are not statistically significant at conventional levels, implying the impact of the treatment does not differ by sector of activity, both estimated coefficients are negative with the magnitude of the interaction between the treatment and the private sector equal to that of the treatment alone. However, we find that the total impact of the treatment for both participants from the nonprofit sector and those

\footnotetext{
${ }^{6}$ In robustness checks, we estimate both probit and logit models, and find similar results. We present the linear probability model results as it facilitates the interpretation of the interaction terms.
} 
from the private sector is not significantly different from zero (in both columns 2 and 3). Therefore, the increase in the probability of keeping the full amount due to the treatment is only statistically significant for students.

In addition to these regression results, we conduct significance tests for the treatment, for each sector separately, and find that there is no significant treatment effect for those participants from the private sector, confirming the findings in table 8 . For students, the two tailed t-test and the Mann-Whitney test are insignificant, but the one-sided p-value of the treatment effect ( $H_{1}$ : The treatment effect is positive) is significant at the $10 \%$ level ( $\mathrm{p}=0.0758$ ). The results are similar for those participants from the nonprofit sector with both a two tailed t-test and a Mann-Whitney test for a non-zero treatment effect being insignificant, but the one-sided p-value of the treatment effect is significant at the $10 \%$ level $(\mathrm{p}=0.0627)$. In column 3, we add controls for age, gender, and nationality, and find that the treatment results are broadly unchanged. We also find that women are less likely to keep the full amount.

In table 9 , we control for age, gender, nationality, education, and also include the same set of questions on attitudes to NGOs and poverty, as for the donation regressions in table 7. Female participants are again less likely to give nothing away. Attitudes towards poverty and NGO performance are not significantly related to whether a participant chose to keep the full endowment.

Having examined the determinants of keeping the full amount, we now turn to a brief discussion of those individuals who gave their own money to their chosen charity. Recall that the final question of the questionnaire asked participants if they wanted to add some of their own money to that which they had allocated from their endowment. Only seven individuals, or $16 \%$ of those who donated the full endowment (4.7\% of the total sample), chose to do so. Given this small sample, we are unable to examine the correlates of giving of these additional funds econometrically. Nonetheless, this is an interesting finding in itself, 
indicating that people who are "generous" by giving away all of the windfall gain allocated to them in an economic experiment are more generous with such an endowment than with their own money. However, we cannot exclude the possibility that participants felt that 20,000 UGX was already sufficient to give to an NGO. Of the seven individuals who gave their own funds, six were male, six were Ugandan (the one female who contributed her own funds was not Ugandan). No students gave their own funds, and only one civil servant from the Ministry of Finance did so. The significance of these characteristics cannot be tested given the few positive observations of own contributions, but do seem to reflect the findings of the donation regressions presented above.

\section{Conclusions}

We play a modified dictator game in urban Uganda with the partner being a charity operating locally. Our subjects include university students and non-students who participated either at the Ministry of Finance or in a cafe in Kampala. The average donation amount is just under one-half of the endowment; somewhat higher than has been found elsewhere in the literature. This result is unsurprising given the the "worthiness" of the recipient, a charity.

Our experimental design allowed us to test four hypotheses concerning behaviour. Our first hypothesis, that the provision of an "exit option" should decrease the amount donated, is not rejected in the simple means tests. However, the treatment becomes insignificant when controlling for group differences and individual characteristics. Given our small sample size and the minor changes in the magnitudes of the coefficients of interest, this is likely due to a lack of power.

Allowing the amount given to exceed the endowment was hypothesized to increase the amount donated. Despite $30 \%$ of participants donating their full endowment to the charity, 
only seven participants, $4.7 \%$ of the total sample, added their own funds to the amount they chose to donate from the unearned endowment. This result may indicate that participants felt that 20,000 UGX was a sufficient donation amount or that they treated the "windfall" endowment in the game differently from their own income, or both.

Furthermore, our results suggest, that an individual's ranking of the charity is negatively correlated with the amount given for non-Ugandans. We suggest one possible explanation for this counter-intuitive finding. Individuals who believe that NGOs are doing good work in Uganda may believe that they are able to do so because they are already well funded. Similarly, individuals who believe that NGOs are not doing good work in Uganda may do so because they believe they do not have sufficient funding. Unfortunately, we do not have data to test this explanation. We do not find strong evidence supporting the hypothesis, that the amount given is increasing in the perceived 'worthiness' of the recipient. A participant agreeing with the statement that "People are poor through no fault of their own" did not donate significantly more, in a regression with individual controls.

Earnings amongst our participants are likely lowest for students, so we might expect this subgroup to donate the least (in line with the findings of many other studies). However, we find that civil servants are significantly less generous than students, donating 3,000 UGX less, or approximately $30 \%$ of the average donation amount. This is in contrast with the findings of Banuri and Keefer (2015), who find civil servants to be more generous. Interestingly, the students who participated in our game were students in the economics department at Makerere University, which is where many of the personnel within the Ministry of Finance studied. Therefore, expected lifetime earnings are plausibly similar for students and Ministry of Finance personnel and are also unlikely to explain the differential findings. One possible explanation is that the Ministry of Finance personnel are more likely to be expected to financially assist others in their extended families and social networks compared to students (Jakiela and Ozier, 2012). It is possible that Ministry of Finance personnel, and others, 
chose to use the funds they kept from the game to assist members of their network instead of a charity. Finally, other non-students, likely our wealthiest subgroup, show the opposite behaviour, being more generous in their giving to charities.

Our results provide some modest evidence that non-poor people in a developing country do give fairly generously to charity when given the option from a windfall gain, though they are much less likely to give from their own purses, and less likely to give when they have an option not to see the person in need. These findings suggest interesting areas of future research. One extension would be to vary the amount of the endowment in order to investigate whether participants did not contribute their own funds because of the belief that the full endowment was sufficient funding for the charity. Moreover, a larger sample size and detailed participant attitudes towards NGOs, including the adequacy of their funding, would shed further light on this issue and would allow for additional exploration of behavioural differences between these interesting and understudied sub-populations in developing countries. 


\section{References}

Ashraf, N., Bohnet, I., and Piankov, N. (2006). Decomposing trust and trustworthiness. Experimental Economics, 9(3):193-208.

Banuri, S. and Keefer, P. (2015). Pro-social motivation, effort and the call to public service. European Economic Review.

Bardsley, N. (2008). Dictator game giving: altruism or artefact? Experimental Economics, 11(2):122-133.

Bekkers, R. et al. (2007). Measuring altruistic behavior in surveys: The all-or-nothing dictator game. In Survey Research Methods, volume 1, pages 139-144. University of Groningen.

Bekkers, R. and Wiepking, P. (2011). A literature review of empirical studies of philanthropy: Eight mechanisms that drive charitable giving. Nonprofit and Voluntary Sector Quarterly, 40(5):924-973.

Belot, M., Duch, R., and Miller, L. (2015). A comprehensive comparison of students and nonstudents in classic experimental games. Journal of Economic Behavior \& Organization, 113:26-33.

Besley, T. and Ghatak, M. (2005). Competition and incentives with motivated agents. American Economic Review, 95(3):616-636.

Broberg, T., Ellingsen, T., and Johannesson, M. (2007). Is generosity involuntary? Economics Letters, 94(1):32 - 37.

Camerer, C. (2003). Behavioral game theory: Experiments in strategic interaction. Princeton University Press. 
Cardenas, J. C. and Carpenter, J. (2008). Behavioural development economics: Lessons from field labs in the developing world. The Journal of Development Studies, 44(3):311-338.

Carlsson, F., He, H., and Martinsson, P. (2013). Easy come, easy go. Experimental Economics, 16(2):190-207.

Carpenter, J., Connolly, C., and Myers, C. (2008). Altruistic behavior in a representative dictator experiment. Experimental Economics, 11(3):282-298.

Cherry, T. L., Frykblom, P., and Shogren, J. F. (2002). Hardnose the dictator. American Economic Review, pages 1218-1221.

Cilliers, J., Dube, O., and Siddiqi, B. (2013). 'White Man's Burden'? A Field Experiment on Generosity and Foreigner Presence. Centre for the Study of African Economies conference paper.

Clark, J. (2002). House money effects in public good experiments. Experimental Economics, $5(3): 223-231$.

Cowley, E. and Smith, S. (2014). Motivation and mission in the public sector: evidence from the world values survey. Theory and Decision, 76(2):241-263.

Dana, J., Cain, D. M., and Dawes, R. M. (2006). What you don't know won't hurt me: Costly (but quiet) exit in dictator games. Organizational Behavior and Human Decision Processes, 100(2):193-201.

Duch, R. M. and Palmer, H. D. (2004). It's not whether you win or lose, but how you play the game: Self-interest, social justice, and mass attitudes toward market transition. American Political Science Review, 98(3):437-452.

Eckel, C. C. and Grossman, P. J. (1996). Altruism in anonymous dictator games. Games and Economic Behavior, 16(2):181-191. 
Einolf, C. J. (2016). Cross-national differences in charitable giving in the west and the world. VOLUNTAS: International Journal of Voluntary and Nonprofit Organizations, pages 1-20.

Engel, C. (2011). Dictator games: a meta study. Experimental Economics, 14(4):583-610.

Falk, A., Meier, S., and Zehnder, C. (2013). Do lab experiments misrepresent social preferences? the case of self-selected student samples. Journal of the European Economic Association, 11(4):839-852.

Fehr, E. and Schmidt, K. M. (1999). A theory of fairness, competition, and cooperation. Quarterly Journal of Economics, pages 817-868.

Fong, C. M. and Luttmer, E. F. (2011). Do fairness and race matter in generosity? evidence from a nationally representative charity experiment. Journal of Public Economics, 95(5):372-394.

Harrison, G. W. (2007). House money effects in public good experiments: Comment. Experimental Economics, 10(4):429-437.

Henrich, J., Boyd, R., Bowles, S., Camerer, C., Fehr, E., Gintis, H., and McElreath, R. (2001). In search of homo economicus: behavioral experiments in 15 small-scale societies. American Economic Review, pages 73-78.

Henrich, J., Boyd, R., Bowles, S., Camerer, C., Fehr, E., Gintis, H., McElreath, R., Alvard, M., Barr, A., Ensminger, J., Henrich, N. S., Hill, K., Gil-White, F., Gurven, M., Marlowe, F. W., Patton, J. Q., and Tracer, D. (2005). "economic man" in cross-cultural perspective: Behavioral experiments in 15 small-scale societies. Behavioral and Brain Sciences, 28:795815.

Jacobsen, K. J., Eika, K. H., Helland, L., Lind, J. T., and Nyborg, K. (2011). Are nurses more altruistic than real estate brokers? Journal of Economic Psychology, 32(5):818-831. 
Jakiela, P. and Ozier, O. W. (2012). Does Africa need a rotten kin theorem? experimental evidence from village economies. World Bank Policy Research Working Paper, (6085).

Levitt, S. D. and List, J. A. (2007). What do laboratory experiments measuring social preferences reveal about the real world? The Journal of Economic Perspectives, 21(2):pp. $153-174$.

List, J. A. (2007). On the interpretation of giving in dictator games. Journal of Political Economy, 115(3):482-493.

Mattes, R. (2015). South africa's emerging black middle class: A harbinger of political change? Journal of International Development, 27(5):665-692.

Resnick, D. (2015). The political economy of africa's emergent middle class: Retrospect and prospects. Journal of International Development, 27(5):573-587.

Serra, D., Serneels, P., and Barr, A. (2011). Intrinsic motivations and the non-profit health sector: Evidence from Ethiopia. Personality and Individual Differences, 51(3):309-314.

Small, D. A. and Loewenstein, G. (2003). Helping a victim or helping the victim: Altruism and identifiability. Journal of Risk and Uncertainty, 26(1):5-16.

Small, D. A., Loewenstein, G., and Slovic, P. (2007). Sympathy and callousness: The impact of deliberative thought on donations to identifiable and statistical victims. Organizational Behavior and Human Decision Processes, 102(2):143-153.

Zizzo, D. J. (2013). Do dictator games measure altruism? In Bruni, L. and Zamagni, S., editors, Handbook of the economics of giving, altruism and reciprocity: Foundations. Edward Elgar. 
Table 1: Descriptive Statistics by Treatment Status (Full Sample)

(1)

(3)

(4)

Full Sample Treatment Group Control Group Difference

\begin{tabular}{lcccc}
\hline Makerere University & 0.26 & 0.33 & 0.21 & 0.12 \\
Ministry of Finance & $(0.44)$ & $(0.47)$ & $(0.41)$ & \\
Cafe & 0.36 & 0.34 & 0.37 & -0.03 \\
Female & $(0.48)$ & $(0.48)$ & $(0.49)$ & \\
& 0.38 & 0.33 & 0.42 & -0.09 \\
Ugandan & $(0.49)$ & $(0.47)$ & $(0.50)$ & \\
Age & 0.46 & 0.50 & 0.43 & 0.07 \\
Completed High School or Less & $(0.50)$ & $(0.50)$ & $(0.50)$ & \\
& 0.71 & 0.72 & 0.70 & 0.02 \\
Undergraduate Degree & $(0.46)$ & $(0.45)$ & $(0.46)$ & \\
& 32.14 & 30.02 & 33.47 & $-3.45^{* *}$ \\
Postgraduate Degree & $(10.12)$ & $(8.82)$ & $(10.69)$ & \\
& 0.35 & 0.31 & 0.37 & -0.06 \\
Nonprofit Sector & $0.48)$ & $(0.47)$ & $(0.49)$ & \\
& 0.43 & 0.50 & 0.38 & 0.12 \\
Private Sector & $(0.50)$ & $(0.50)$ & $(0.49)$ & \\
& 0.21 & 0.19 & 0.23 & -0.04 \\
Student & $(0.41)$ & $(0.40)$ & $(0.42)$ & \\
Observations & 0.50 & 0.41 & 0.55 & -0.14 \\
& $(0.50)$ & $(0.50)$ & $(0.50)$ & \\
& 0.24 & 0.24 & 0.24 & 0.01 \\
& $(0.43)$ & $(0.43)$ & $(0.43)$ & \\
& 0.27 & 0.34 & 0.22 & 0.12 \\
& $(0.45)$ & $(0.48)$ & $(0.42)$ & \\
& 149 & 58 & 91 & \\
\end{tabular}

Notes: ${ }^{*}$ significant at $10 \%,{ }^{* *}$ significant at $5 \%,{ }^{* * *}$ significant at $1 \%$. 
Table 2: Descriptive Statistics by Treatment Status (Complete Questionnaire Sub-Sample)

(1)

(3)

(4)

Full Sample Treatment Group Control Group Difference

\begin{tabular}{|c|c|c|c|c|}
\hline Makerere University & $\begin{array}{c}0.27 \\
(0.45)\end{array}$ & $\begin{array}{c}0.37 \\
(0.49)\end{array}$ & $\begin{array}{c}0.22 \\
(0.42)\end{array}$ & $0.15^{*}$ \\
\hline Ministry of Finance & $\begin{array}{c}0.33 \\
(0.47)\end{array}$ & $\begin{array}{c}0.28 \\
(0.45)\end{array}$ & $\begin{array}{c}0.36 \\
(0.48)\end{array}$ & -0.08 \\
\hline Cafe & $\begin{array}{c}0.40 \\
(0.49)\end{array}$ & $\begin{array}{c}0.35 \\
(0.48)\end{array}$ & $\begin{array}{c}0.42 \\
(0.50)\end{array}$ & -0.07 \\
\hline Female & $\begin{array}{c}0.40 \\
(0.49)\end{array}$ & $\begin{array}{c}0.44 \\
(0.50)\end{array}$ & $\begin{array}{c}0.38 \\
(0.49)\end{array}$ & 0.06 \\
\hline Ugandan & $\begin{array}{c}0.69 \\
(0.47)\end{array}$ & $\begin{array}{c}0.67 \\
(0.47)\end{array}$ & $\begin{array}{c}0.69 \\
(0.46)\end{array}$ & -0.02 \\
\hline Age & $\begin{array}{c}32.18 \\
(10.16)\end{array}$ & $\begin{array}{c}30.44 \\
(9.40)\end{array}$ & $\begin{array}{l}33.14 \\
(10.49)\end{array}$ & -2.70 \\
\hline Completed High School or Less & $\begin{array}{c}0.31 \\
(0.47)\end{array}$ & $\begin{array}{c}0.28 \\
(0.45)\end{array}$ & $\begin{array}{c}0.33 \\
(0.47)\end{array}$ & -0.05 \\
\hline Undergraduate Degree & $\begin{array}{c}0.46 \\
(0.50)\end{array}$ & $\begin{array}{c}0.51 \\
(0.51)\end{array}$ & $\begin{array}{c}0.44 \\
(0.50)\end{array}$ & 0.08 \\
\hline Postgraduate Degree & $\begin{array}{c}0.22 \\
(0.42)\end{array}$ & $\begin{array}{c}0.21 \\
(0.41)\end{array}$ & $\begin{array}{c}0.23 \\
(0.42)\end{array}$ & -0.02 \\
\hline Nonprofit Sector & $\begin{array}{c}0.49 \\
(0.50)\end{array}$ & $\begin{array}{c}0.37 \\
(0.49)\end{array}$ & $\begin{array}{c}0.55 \\
(0.50)\end{array}$ & $-0.18^{*}$ \\
\hline Private Sector & $\begin{array}{c}0.24 \\
(0.43)\end{array}$ & $\begin{array}{c}0.23 \\
(0.43)\end{array}$ & $\begin{array}{c}0.24 \\
(0.43)\end{array}$ & -0.01 \\
\hline Student & $\begin{array}{c}0.28 \\
(0.45)\end{array}$ & $\begin{array}{c}0.40 \\
(0.49)\end{array}$ & $\begin{array}{c}0.22 \\
(0.42)\end{array}$ & $0.18^{* *}$ \\
\hline Observations & 121 & 43 & 78 & \\
\hline
\end{tabular}

Notes: $*$ significant at $10 \%, * *$ significant at $5 \%, * * *$ significant at $1 \%$. 
Table 3: Game Decisions by Treatment Status

(1)

(3)

(4)

Full Sample Treatment Group Control Group Difference

\begin{tabular}{|c|c|c|c|c|}
\hline & \multicolumn{4}{|c|}{ Panel A } \\
\hline Amount Donated & $\begin{array}{l}9,114.09 \\
(7,886.47)\end{array}$ & $\begin{array}{l}7,568.97 \\
(7,793.64)\end{array}$ & $\begin{array}{c}10,098.90 \\
(7,828.80)\end{array}$ & $-2,529.94$ \\
\hline Gave Away Full Amount & $\begin{array}{l}0.30 \\
(0.46)\end{array}$ & $\begin{array}{l}0.22 \\
(0.42)\end{array}$ & $\begin{array}{l}0.34 \\
(0.48)\end{array}$ & -0.12 \\
\hline Kept Full Amount & $\begin{array}{l}0.16 \\
(0.37)\end{array}$ & $\begin{array}{l}0.24 \\
(0.43)\end{array}$ & $\begin{array}{c}0.11 \\
(0.31)\end{array}$ & $0.13^{* *}$ \\
\hline Opened Envelope & & 0.78 & & \\
\hline Observations & 149 & 58 & 91 & \\
\hline & \multicolumn{4}{|c|}{ Panel B } \\
\hline Amount Donated & $\begin{array}{l}9,297.52 \\
(8,015.24)\end{array}$ & $\begin{array}{l}8,093.02 \\
(8,129.35)\end{array}$ & $\begin{array}{l}9,961.54 \\
(7,925.70)\end{array}$ & $-1,868.52$ \\
\hline Gave Away Full Amount & $\begin{array}{l}0.31 \\
(0.47)\end{array}$ & $\begin{array}{l}0.26 \\
(0.44)\end{array}$ & $\begin{array}{l}0.35 \\
(0.48)\end{array}$ & -0.09 \\
\hline Kept Full Amount & $\begin{array}{l}0.16 \\
(0.37)\end{array}$ & $\begin{array}{l}0.23 \\
(0.43)\end{array}$ & $\begin{array}{l}0.12 \\
(0.32)\end{array}$ & $0.12^{*}$ \\
\hline Opened Envelope & & 0.77 & & \\
\hline Observations & 121 & 43 & 78 & \\
\hline
\end{tabular}

Notes: ${ }^{*}$ significant at $10 \%,{ }^{* *}$ significant at $5 \%,{ }^{* * *}$ significant at $1 \%$. 
Table 4: Game Decisions by Envelope Choice

(1)

(2)

(3)

(4)

\begin{tabular}{|c|c|c|c|c|}
\hline & Treatment Sample & Did Not Open & Opened & Difference \\
\hline & \multicolumn{4}{|c|}{ Panel A } \\
\hline Amount Donated & $\begin{array}{l}7,568.97 \\
(7,793.64)\end{array}$ & $\begin{array}{l}2,615.38 \\
(4,426.03)\end{array}$ & $\begin{array}{l}9,000.00 \\
(8,000.00)\end{array}$ & $-6,384.62^{* * *}$ \\
\hline Gave Away Full Amount & $\begin{array}{l}0.22 \\
(0.42)\end{array}$ & $\begin{array}{c}0.00 \\
(0.00)\end{array}$ & $\begin{array}{l}0.29 \\
(0.46)\end{array}$ & $-0.29^{* *}$ \\
\hline Kept Full Amount & $\begin{array}{c}0.24 \\
(0.43)\end{array}$ & $\begin{array}{l}0.54 \\
(0.52)\end{array}$ & $\begin{array}{l}0.16 \\
(0.37)\end{array}$ & $0.38^{* * *}$ \\
\hline \multirow[t]{3}{*}{ Observations } & 58 & 13 & 45 & \\
\hline & \multicolumn{4}{|c|}{ Panel B } \\
\hline & Identity Sample & Opened & Control & Difference \\
\hline Amount Donated & $\begin{array}{l}9,735.29 \\
(7,873.29)\end{array}$ & $\begin{array}{l}9,000.00 \\
(8,000.00)\end{array}$ & $\begin{array}{c}10,098.90 \\
(7,828.80)\end{array}$ & $-1,098.90$ \\
\hline Gave Away Full amount & $\begin{array}{l}0.32 \\
(0.47)\end{array}$ & $\begin{array}{c}0.29 \\
(0.46)\end{array}$ & $\begin{array}{c}0.34 \\
(0.48)\end{array}$ & -0.05 \\
\hline Kept Full Amount & $\begin{array}{l}0.13 \\
(0.33)\end{array}$ & $\begin{array}{l}0.16 \\
(0.37)\end{array}$ & $\begin{array}{l}0.11 \\
(0.31)\end{array}$ & 0.05 \\
\hline Observations & 136 & 45 & 91 & \\
\hline
\end{tabular}

Notes: ${ }^{*}$ significant at $10 \%,{ }^{* *}$ significant at $5 \%,{ }^{* * *}$ significant at $1 \%$.

The identity sample is composed of the control group and those participants in the treatment group who chose to open the identity envelope. 
Table 5: Impact of Treatment by Sector

\begin{tabular}{|c|c|c|c|}
\hline & (1) & $(2)$ & $(3)$ \\
\hline \multirow[t]{2}{*}{ Treatment } & $-2,529.94^{*}$ & $-2,303.11^{*}$ & $-2,975.30$ \\
\hline & $(1,310.87)$ & $(1,235.93)$ & $(2,340.93)$ \\
\hline \multirow[t]{2}{*}{ Nonprofit Sector } & & 636.94 & 106.71 \\
\hline & & $(1,414.64)$ & $(1,908.10)$ \\
\hline \multirow[t]{2}{*}{ Private Sector } & & $4,637.91^{* *}$ & $4,373.04^{*}$ \\
\hline & & $(1,904.47)$ & $(2,497.96)$ \\
\hline \multirow[t]{2}{*}{ Treatment*Nonprofit Sector } & & & $1,201.92$ \\
\hline & & & $(2,862.83)$ \\
\hline \multirow[t]{2}{*}{ Treatment*Private Sector } & & & 415.35 \\
\hline & & & $(3,726.49)$ \\
\hline \multirow[t]{2}{*}{ Ugandan } & & $-4,640.22^{* * *}$ & $-4,703.61^{* * *}$ \\
\hline & & $(1,529.37)$ & $(1,536.01)$ \\
\hline \multirow[t]{2}{*}{ Constant } & $10,098.90^{* * *}$ & $11,849.18^{* * *}$ & $12,253.01^{* * *}$ \\
\hline & $(821.69)$ & $(1,862.86)$ & $(2,141.49)$ \\
\hline$R^{2}$ & 0.02 & 0.17 & 0.17 \\
\hline Sample Size & 149 & 146 & 146 \\
\hline \multicolumn{4}{|c|}{ Notes: Dependent variable is the amount donated (UGX). } \\
\hline \multicolumn{4}{|c|}{ Table 6: Impact of Treatment by Sector (Ugandan Sub-Sample) } \\
\hline \multirow{3}{*}{ Treatment } & $(1)$ & $(2)$ & $(3)$ \\
\hline & $-2,150.79$ & $-2,083.29$ & $-1,666.67$ \\
\hline & $(1,378.88)$ & $(1,322.68)$ & $(2,353.78)$ \\
\hline \multirow[t]{2}{*}{ Nonprofit Sector } & & $-1,359.84$ & -885.71 \\
\hline & & $(1,427.55)$ & $(1,986.05)$ \\
\hline \multirow[t]{2}{*}{ Private Sector } & & $4,420.84^{*}$ & $4,153.85$ \\
\hline & & $(2,268.20)$ & $(3,010.74)$ \\
\hline \multirow[t]{2}{*}{ Treatment*Nonprofit Sector } & & & $-1,147.62$ \\
\hline & & & $(2,881.02)$ \\
\hline \multirow[t]{2}{*}{ Treatment*Private Sector } & & & 941.39 \\
\hline & & & $(4,643.22)$ \\
\hline \multirow[t]{2}{*}{ Constant } & $8,365.08^{* * *}$ & $8,208.31^{* * *}$ & $8,000.00 * * *$ \\
\hline & $(890.09)$ & $(1,350.91)$ & $(1,692.92)$ \\
\hline$R^{2}$ & 0.02 & 0.12 & 0.12 \\
\hline Sample Size & 105 & 105 & 105 \\
\hline
\end{tabular}

Notes: Dependent variable is the amount donated (UGX).

Robust standard errors in parentheses. $*$ significant at $10 \%, * *$ significant at $5 \%, * * *$ significant at $1 \%$. 
Table 7: Personal Characteristics Correlated with Amount Donated

\begin{tabular}{|c|c|c|c|c|c|}
\hline & (1) & $(2)$ & $(3)$ & (4) & $(5)$ \\
\hline Nonprofit Sector & $\begin{array}{c}-575.51 \\
(1,870.63)\end{array}$ & $\begin{array}{l}7,641.23^{* *} \\
(3,640.69)\end{array}$ & & & \\
\hline Nonprofit Sector*Ugandan & & $\begin{array}{c}-11945.52^{* * *} \\
(3,874.96)\end{array}$ & & & \\
\hline Private Sector & $\begin{array}{c}3,713.54 \\
(2,486.24)\end{array}$ & $\begin{array}{c}6,016.79 \\
(4,012.01)\end{array}$ & & & \\
\hline Private Sector*Ugandan & & $\begin{array}{l}-2,892.21 \\
(4,561.91)\end{array}$ & & & \\
\hline Ugandan & $\begin{array}{c}-4,781.78^{* * *} \\
(1,616.80)\end{array}$ & $\begin{array}{c}2,193.55 \\
(3,272.72)\end{array}$ & $\begin{array}{c}-3,500.83^{* *} \\
(1,572.43)\end{array}$ & $\begin{array}{c}-5,857.99^{* *} \\
(2,308.67)\end{array}$ & $\begin{array}{c}-5,654.98^{* *} \\
(2,435.03)\end{array}$ \\
\hline Female & $\begin{array}{c}1,597.73 \\
(1,378.54)\end{array}$ & $\begin{array}{c}895.79 \\
(1,340.32)\end{array}$ & $\begin{array}{c}668.93 \\
(1,333.38)\end{array}$ & $\begin{array}{c}547.41 \\
(1,305.53)\end{array}$ & $\begin{array}{c}503.70 \\
(1,274.46)\end{array}$ \\
\hline Age & $\begin{array}{c}137.56^{*} \\
(77.55)\end{array}$ & $\begin{array}{c}221.02^{* * *} \\
(83.99)\end{array}$ & $\begin{array}{l}124.59^{*} \\
(62.90)\end{array}$ & $\begin{array}{c}88.80 \\
(64.93)\end{array}$ & $\begin{array}{c}52.62 \\
(68.47)\end{array}$ \\
\hline Treatment & $\begin{array}{l}-1,736.37 \\
(1,404.72)\end{array}$ & $\begin{array}{l}-1,094.86 \\
(1,274.76)\end{array}$ & $\begin{array}{l}-1,148.62 \\
(1,394.69)\end{array}$ & $\begin{array}{l}-1,502.26 \\
(1,347.00)\end{array}$ & $\begin{array}{l}-1,598.93 \\
(1,295.43)\end{array}$ \\
\hline $\begin{array}{l}\text { People poor no fault } \\
\text { (Strongly Agree) }\end{array}$ & & & $\begin{array}{l}2,766.82^{*} \\
(1,566.21)\end{array}$ & $\begin{array}{c}2,422.22 \\
(2,275.81)\end{array}$ & $\begin{array}{c}414.94 \\
(2,703.35)\end{array}$ \\
\hline $\begin{array}{l}\text { People poor no fault } \\
\text { (Strongly Agree)*Ugandan }\end{array}$ & & & & $\begin{array}{c}196.95 \\
(3,036.93)\end{array}$ & $\begin{array}{c}1,597.72 \\
(3,122.40)\end{array}$ \\
\hline $\begin{array}{l}\text { NGOs Do Good } \\
\text { (Strongly Agree) }\end{array}$ & & & $\begin{array}{c}-4,542.88^{* * *} \\
(1,363.19)\end{array}$ & $\begin{array}{c}-9,998.04^{* * *} \\
(2,562.15)\end{array}$ & $\begin{array}{c}-8,235.56^{* * *} \\
(2,633.60)\end{array}$ \\
\hline NGOs Do Good (Strongly & & & & $7,361.17^{* *}$ & $7,049.29^{* *}$ \\
\hline Agree)*Ugandan & & & & $(3,044.07)$ & $(3,035.53)$ \\
\hline Undergraduate Degree & & & & & $\begin{array}{c}-78.84 \\
(1,558.38)\end{array}$ \\
\hline Postgraduate Degree & & & & & $\begin{array}{c}5,251.47^{* *} \\
(2,254.49)\end{array}$ \\
\hline Constant & $\begin{array}{c}7,511.20^{* *} \\
(3,016.63)\end{array}$ & $\begin{array}{c}-55.49 \\
(3,603.86)\end{array}$ & $\begin{array}{c}8,594.68^{* * *} \\
(2,747.66)\end{array}$ & $\begin{array}{c}11,460.27^{* * *} \\
(3,311.49)\end{array}$ & $\begin{array}{c}11,295.30^{* * *} \\
(3,844.81)\end{array}$ \\
\hline$R^{2}$ & 0.19 & 0.27 & 0.23 & 0.27 & 0.32 \\
\hline Sample Size & 121 & 121 & 119 & 119 & 119 \\
\hline
\end{tabular}

Notes: Dependent variable is the amount donated (UGX). * significant at $10 \%$, Robust standard errors in parentheses. ${ }^{*}$ significant at $10 \% * *$ significant at $5 \%,{ }^{* * *}$ significant at $1 \%$. 
Table 8: LPM Estimates of Keeping the Full Amount by Sector (Full Sample)

\begin{tabular}{lccc}
\hline & $(1)$ & $(2)$ & $(3)$ \\
Nonprofit Sector & -0.09 & -0.04 & 0.03 \\
Private Sector & $(0.08)$ & $(0.08)$ & $(0.09)$ \\
& -0.10 & 0.01 & 0.01 \\
Treatment & $(0.09)$ & $(0.11)$ & $(0.12)$ \\
& $0.13^{*}$ & $0.23^{*}$ & $0.22^{*}$ \\
Treatment*Nonprofit Sector & $(0.07)$ & $(0.13)$ & $(0.13)$ \\
& & -0.09 & -0.11 \\
Treatment*Private Sector & & $(0.16)$ & $(0.16)$ \\
& & -0.24 & -0.22 \\
Female & & & $-0.15^{* *}$ \\
& & & $(0.07)$ \\
Age & & & $-0.01^{* *}$ \\
& & & $(0.00)$ \\
Ugandan & -0.10 & -0.10 & -0.09 \\
& $(0.07)$ & $(0.07)$ & $(0.07)$ \\
Constant & $0.25^{* *}$ & $0.19^{*}$ & $0.43^{* * *}$ \\
& $(0.10)$ & $(0.10)$ & $(0.13)$ \\
$R^{2}$ & 0.06 & 0.07 & 0.12 \\
Sample Size & 146 & 146 & 143 \\
\hline * significant at 10\%, ** significant at $5 \%, * * *$ & significant \\
at 1\%. Robust standard errors in parentheses. &
\end{tabular}


Table 9: LPM Estimates of Keeping the Full Amount (Sub-Sample with Additional Controls)

\begin{tabular}{|c|c|c|c|}
\hline & (1) & $(2)$ & $(3)$ \\
\hline \multirow[t]{2}{*}{ Non-Ugandan } & 0.05 & 0.07 & 0.02 \\
\hline & $(0.07)$ & $(0.08)$ & $(0.12)$ \\
\hline \multirow[t]{2}{*}{ Female } & $-0.15^{* *}$ & $-0.17^{* *}$ & $-0.15^{* *}$ \\
\hline & $(0.06)$ & $(0.06)$ & $(0.07)$ \\
\hline \multirow[t]{2}{*}{ Age } & $-0.01 * * *$ & $-0.01 * * *$ & $-0.00 * *$ \\
\hline & $(0.00)$ & $(0.00)$ & $(0.00)$ \\
\hline \multirow[t]{2}{*}{ Treatment } & 0.09 & 0.09 & 0.10 \\
\hline & $(0.07)$ & $(0.07)$ & $(0.07)$ \\
\hline People poor no fault & & -0.01 & 0.03 \\
\hline (Strongly Agree) & & $(0.07)$ & $(0.10)$ \\
\hline People poor no fault & & & -0.05 \\
\hline (Strongly Agree) $*$ Non-Ugandan & & & $(0.17)$ \\
\hline \multirow[t]{2}{*}{ NGOs Do Good (Strongly Agree) } & & 0.11 & 0.01 \\
\hline & & $(0.07)$ & $(0.09)$ \\
\hline NGOs Do Good (Strongly Agree) & & & 0.27 \\
\hline * Non-Ugandan & & & $(0.19)$ \\
\hline \multirow[t]{2}{*}{ Undergraduate Degree } & & & 0.04 \\
\hline & & & $(0.08)$ \\
\hline \multirow[t]{2}{*}{ Postgraduate Degree } & & & -0.04 \\
\hline & & & $(0.11)$ \\
\hline \multirow[t]{2}{*}{ Constant } & $0.40 * * *$ & $0.35^{* * *}$ & $0.30 * *$ \\
\hline & $(0.11)$ & $(0.11)$ & $(0.13)$ \\
\hline$R^{2}$ & 0.09 & 0.11 & 0.14 \\
\hline Sample Size & 122 & 120 & 120 \\
\hline
\end{tabular}

